\title{
Detection of differentially expressed proteins in sera of patients with hepatocellular carcinoma by sodium dodecyl sulphate poly-acrylamide gel electrophoresis (SDS-PAGE)
}

Farah Sabeen Bugti, Mohammad Zahid Mustafa*, Tauseef Muhammad Asmat, Asadullah, Bibi Zainab, Safiullah Khan Achakzai, Muhammad Rizwan, Abdul Samad, Muhammad Kamran Taj and Nadeem Rashid Center for Advanced studies in Vaccinology and Biotechnology, University of Balochistan Quetta-Pakistan *Corresponding author's email: zunzah@gmail.com

Citation

Farah Sabeen Bugti, Mohammad Zahid Mustafa, Tauseef Muhammad Asmat, Asadullah, Bibi Zainab, Safiullah Khan Achakzai, Muhammad Rizwan, Abdul Samad, Muhammad Kamran Taj and Nadeem Rashid. Detection of differentially expressed proteins in sera of patients with hepatocellular carcinoma by sodium dodecyl sulphate polyacrylamide gel electrophoresis (SDS-PAGE). Pure and Applied Biology. Vol. 6, Issue 1, pp140-145. http://dx.doi.org/10.19045/bspab.2017.60006

Received: 29/11/2016 Revised: 04/01/2017 Accepted: 08/01/2017

Online First: 11/01/2017

\section{Abstract}

Hepatocellular carcinoma (HCC) is considered as one of the major liver cancers prevailing in the world. The survival rate for the patients diagnosed with HCC is very low as average survival time is only one year. Due to the lack of early diagnosis and poor knowledge of pathophysiological mechanisms, screening of HCC remains possible only at advanced stages. Furthermore, due to non-effective treatment and poor diagnostic techniques led to high fatality rate. Previously, number of HCC markers has been identified but have very less specificity.

This study was designed to look into and find out certain HCC specific serological proteins which may be used as biomarker for the early diagnosis of the said disease. In this study all collected samples were analyzed by SDS-PAGE. The results revealed that four different proteins were up-regulated in HCC diagnosed patients compared to the control sample. These proteins may be used as potential biomarkers for the early diagnosis of HCC. The further investigations of the relevant proteins may reveal important clues for the early diagnosis of HCC.

Keywords: Biomarker proteins; HCC; SDS-PAGE; Early diagnosis; Liver Cancer

\section{Introduction}

Hepatocellular carcinoma (HCC) has been reported as one of the most common malignant tumor worldwide [1]. HCC is ranked as sixth most common cancer type and placed among first three cancerous diseases which lead to death in very short time [1]. Poor knowledge, inadequate preliminary screening tests leads to advanced stage of HCC which ultimately results in poor prognosis and high mortality rates [2]. In Great Britain during 1975 HCC 
prevalence rate was only 1.4 per 100,000 which rose to 4.7 per 100,000 during 2009 which reflects a high rise of HCC incidence. Almost 3,960 new cases of liver cancer were reported in the UK during 2009 and caused 3,800 liver cancer deaths during 2010 [3]. Several studies have demonstrated that infectious diseases such as hepatitis B, hepatitis $\mathrm{C}$, presence of aflatoxin in diet and alcohol addiction were the principal etiological factors for $\mathrm{HCC}[4,5]$. Hepatitis $\mathrm{C}$ virus (HCV) related disease is reported as the single largest cause of HCC in Pakistan [6]. In Pakistan, prevalence of $\mathrm{HCV}$ and $\mathrm{HBV}$ is alarming as $4.8 \%$ of population is positive for anti-HCV antibodies and $2.5 \%$ for HBV surface antigen [7, 8]. Almost 70\% of $\mathrm{HCC}$ diagnosed patients were also infected with $\mathrm{HCV}$ while almost $20 \% \mathrm{HCC}$ diagnosed patients were co-infected HBV [9-11]. Due to poor hygienic conditions in Pakistan, high contamination of aflatoxin also contributes to liver carcinogenesis [12, 13]. In Pakistan, the prevalence of $\mathrm{HCC}$ in male is about 7.6 and 2.8/100,000 head in male and female respectively [14-16]. Patients with HCC typically present with an enlarged, irregular and nodular liver [17], and in $75 \%$ HCC cases multifocal liver tumors were observed. Typical HCC diagnosis is usually made by history, physical examination and several imaging techniques such as MRI or CT scan and ultrasound, which come up with consistent liver mass [18] but all these techniques give diagnosis of HCC at advanced stage of the disease when no or limited treatment options remain available. To date no specific serologic biomarker except alpha fetoprotein (up to $75 \%$ specificity) is available for early HCC diagnosis [18]. AFP is a $70-\mathrm{kD}$ glycoprotein produced by the fetal liver and yolk sac during pregnancy $[19,20]$. Several studies highlighted the over expression of many tumor associated antigens (TAA) and the production of auto-antibodies against those TAAs could be used as diagnostic biomarkers.

\section{Materials and methods Sample collection}

Twenty four serum samples were obtained from patients diagnosed with $\mathrm{HCC}$ and 10 were collected from healthy donors at tertiary hospital (Bolan Medical College Quetta). Samples from healthy donors were pooled and used as control. All samples were collected in sterile falcon tubes without anticoagulant or EDTA. After collection, blood samples were centrifuged at 12000 rpm for 5-10 min and collected serum samples were transferred into micro centrifuge tubes and instantly preserved at $80^{\circ} \mathrm{C}$ until used. The estimation of protein concentration in obtained serum samples was determined by using the BCA protein kit bio world (GE Healthcare) according to the standard protocol.

\section{SDS -PAGE}

Sodium dodecyl sulphatepolyacrylamide gel electrophoresis (SDS-PAGE) was used to separate the proteins by their molecular weight. A mini (cleaver scientific Ltd.) system was used for electrophoresis. Two large plates $10 \mathrm{~cm}$ with $1 \mathrm{~mm}$ thick spacer and two $8.5 \mathrm{~cm}$ notched plates were cleaned with $70 \%$ ethanol and were placed in casting frame placed in the casting stand. Two types of Polyacrylamide gels resolving and stacking gel were casted and after gel polymerization samples with equal quantity of protein were loaded. Subsequently, electrophoresis was performed.

Resolving gel (12\% polyacrylamide), Tris $1.5 \mathrm{M} \mathrm{pH}=8.8$ (MP biomedicals, LLC) $25 \%$ (v/v),SDS $\quad 10 \% \quad$ (invitrogen) $1 \%$ (v/v),TEMED (Alpha Aesar) 0.05\% (v/v), ammonium persulfate 10\% (MP biomedicals, LLC) $0.5 \% \quad$ (v/v).Stacking gel $4 \%$ components are follows, Stacking gel (4\% polyacrylamide), Acrylamide (30\%), Bisacrylamide (0.8\%) $13.3 \% \quad(\mathrm{v} / \mathrm{v})$, Tris $0.5 \mathrm{M} \mathrm{pH}=6.8$ (MP biomedicals, LLC) $25 \%$ 
(v/v), SDS 10\% (invitrogen) $1 \% \quad(\mathrm{v} / \mathrm{v})$, TEMED (Alpha Aesar) $0.05 \% \quad(\mathrm{v} / \mathrm{v})$, Ammonium persulfate 10\% (MP biomedicals, LLC) $0.5 \%(\mathrm{v} / \mathrm{v})$. Comassie brilliant blue staining technique was used to visualize the protein bands. Transilluminator apparatus (WEALTEC dolphin-view) was used to take the images of stained gels.

\section{Results and discussion}

Serum samples from HCC diagnosed patients and healthy individuals were analyzed by SDS-PAGE to evaluate the expression of proteins in given samples. Results indicated the upregulation of several proteins in the form of clusters which can further categorized by several other techniques like western blotting and dot blotting. The representative gel loaded with HCC positive and control samples is shown in Figure 1. Several proteins are upregulated in $\mathrm{HCC}$ diagnosed patients as compared to the controls as shown in Figure 1. The most interesting and important one is the AFP with $70 \mathrm{kDa}$ and a thick band in all patients' samples can be observed (marked with arrow heads). The high level of AFP in relation to $\mathrm{HCC}$ has been reported with remarkable sensitivity (41-65\%). Previously, it has been reported that due to high specificity of AFP expression in HCC patients, it's highly recommended to be used as a marker for early diagnosis of HCC. [21] The other protein which attracted our attention was protein phosphate $2 \mathrm{~A}$ (p90/CIP2A) with molecular weight of 90 $\mathrm{kDa}, \mathrm{P} 90 / \mathrm{CIP} 2 \mathrm{~A}$ is a tumor associated antigen (TAA) also known as cancerous inhibitor. In this study we also observed the upregulation of same protein in all $\mathrm{HCC}$ positive samples [22]. This protein is also marked as a candidate for the early diagnosis of HCC [22]. Calreticulin (CRT) is over expressed in HCC cells and our results are also in agreement with previous reports (Figure 1). CRT was observed to be upregulated in all patients' samples at approximate molecular weight of $32 \mathrm{kDa}$ (marked with arrow head). Studies have reported that knockout of CRT with siRNA inhibited the proliferation of HCC cells and leads to cell arrest [23]. These properties of CRT make it a suitable biomarker for the early diagnosis of HCC.

Interestingly, we also found the upregulation of Tu translation elongation factor (TUFM) protein with molecular weight of $50 \mathrm{kDa}$. Previously, TUFM has been reported to be over expressed only in lung cancer cells and for the first time we detected its upregulation in HCC cells. Its further investigations will be performed by Western blot analysis to clearly demonstrate its role in HCC. It has been reported that TUFM and E-cadherin down regulation leads to abruption in mitochondrial respiratory chain activity and the excessive production of reactive oxygen species [24].

These results indicate that the above mentioned proteins can be used as biomarkers for the early diagnosis of HCC and these results are in promise with the studies reported earlier.

Further studies are planned to confirm the specificity of these proteins by modern molecular techniques such as western blot. 


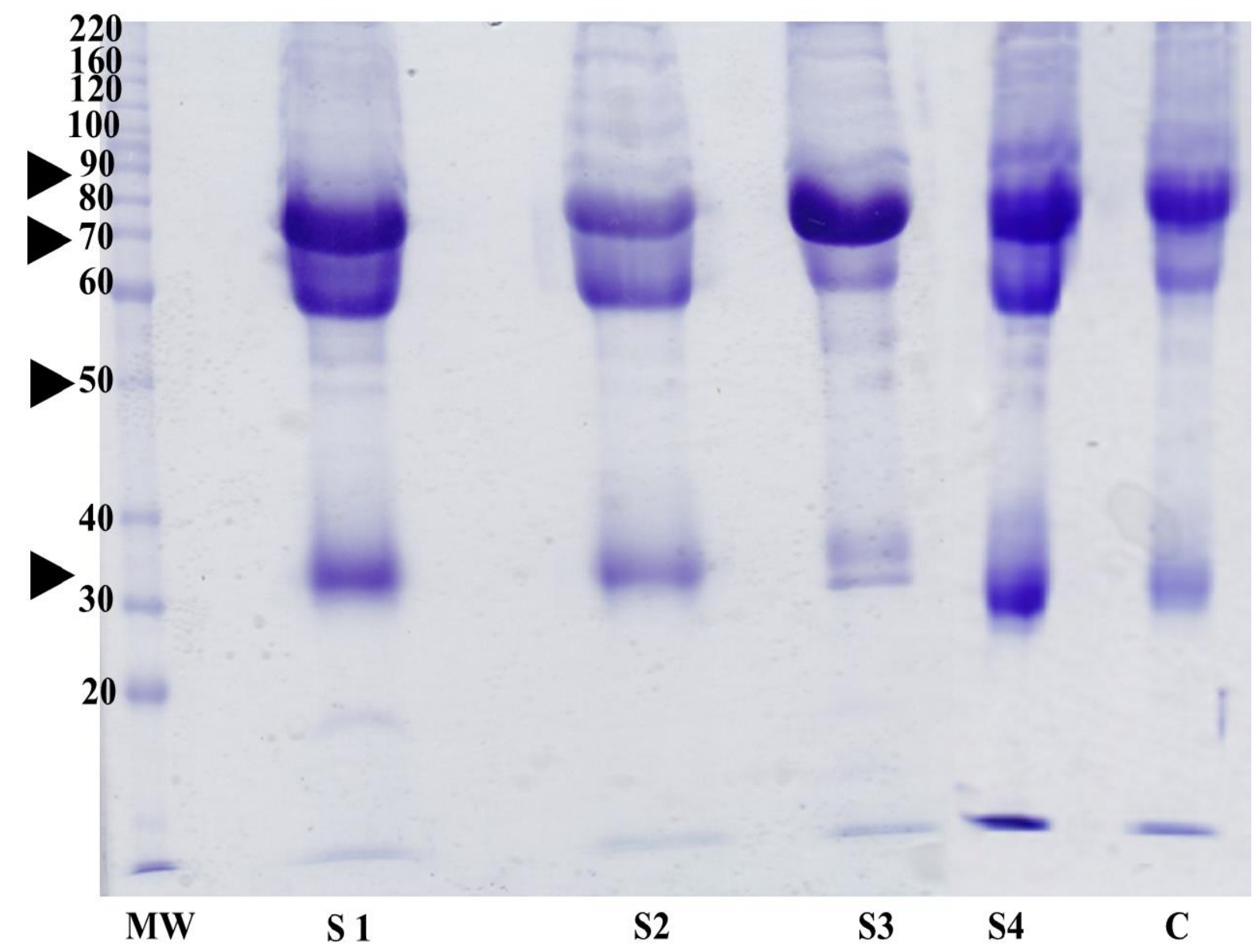

Figure 1. Serum samples collected from HCC diagnosed patients and healthy individual were processed and run on SDS page to compare the protein expression. From left to right is marker for molecular weight (MW), S1, S2, S3, S4 are the samples from HCC diagnosed patients and $\mathrm{C}$ denotes the Control from healthy donor

\section{Conclusion}

The study concludes that proteins regulation pattern can be used a early diagnostic tool and for the first time we report the upregulation of TUFM in HCC diagnosed patients

\section{Authors' contributions}

Conceived and designed the experiments: MZ Mustafa, FS Bugti \& TM Asmat, Performed the experiments: FS Bugti, Analyzed the data: Asadullah, B Zainab, SK Achakzai \& M Rizwan, Contributed reagents/ materials/ analysis tools: A Samad, MK Taj \& N Rashid, Wrote the paper: TM Asmat \& FS Bugti.

\section{Acknowledgements}

We are grateful to Professor. Dr. Sherbat Khan and Dr. Zafar Iqbal, Department of Gastroenterology Bolan Medical Complex Quetta for their kind help regarding sample collection. We are thankful to Prof. Dr. M.M. Tariq Kiani for facilitating in research work.

\section{References}

1. Looi KS, Ernesto S, Nakayasu RA, De D, Eng MT, Igor CA \& Jian YZ (2008). Using Proteomic Approach to Identify Tumor-Associated Antigens as Markers in Hepatocellular Carcinoma. $J$ Proteome Res 7(9): 4004-4012. 
2. Middleton $\mathrm{CH}$, William I, John FRR, Andrea M, Celine PK, Isabel KM, Jane ME, Jared A, Graham FH, Brian JT, Stephen JR, Stefan H \& Caroline JC (2014). Serum Autoantibody Measurement for the Detection of Hepatocellular Carcinoma. PLoSONE 9(8):e103867.doi:10.1371/journal.pone. 0103867.

3. Cancer Research UK (2010, 19/09/09). "Cancer Stats." 2010. Available: http://info.cancerresearchuk.org/cancers tats/index.htm.

4. Lopez LJ \& Marrero JA (2004). Hepatocellular carcinoma. Curr Opin Gastroenterology 20:248-253.

5. Thorgeirsson SS \& Grisham JW (2002). Molecular pathogenesis of human hepatocellular carcinoma. Nat Genet 31: 339-346.

6. Khan A, Tanaka Y, Azam Z, Abbas Z, Kurbanov F \& Saleem U (2009). Epidemic spread of hepatitis $\mathrm{C}$ virus genotype $3 \mathrm{a}$ and relation to high incidence of hepatocellular carcinoma in Pakistan. J Med Virol 81:1189-97.

7. Qureshi H, Bile KM, Jooma R, Alam SE \& Afridi HU (2010). Prevalence of hepatitis $\mathrm{B}$ and $\mathrm{C}$ viral infections in Pakistan: findings of a national survey appealing for effective prevention and control measures. East Mediterr Health J 16: 15-23.

8. Abbas Z, Jafri W \& Hamid S (2010). Management of hepatitis B, Pakistan Society for the Study of Liver Diseases (PSSLD) Practice Guidelines. J Coll Physicians Surg Pak 20: 198-201.

9. Butt AS, Hamid S, Wadalawala AA, Ghufran M, Javed AA \& Farooq O (2013). Hepatocellular carcinoma in Native South Asian Pakistani population; trends, clinico-pathological characteristics and differences in viral marker negative and viral- hepatocellular carcinoma. BMC Res Notes 6: 137.

10. Butt AS, Abbas Z \& Jafri W (2012). Hepatocellular carcinoma in Pakistan: where do we stand? Hepat Mon 12: e6023.

11. Yusuf MA, Badar F, Meerza F, Khokhar RA, Ali FA \& Sarwar S (2007). Survival from hepatocellular carcinoma at a cancer hospital in Pakistan. Asian Pac J Cancer Prev 8: 272-4.

12. Qureshi H, Zuberi SJ, Jafarey NA \& Zaidi SH (1990). Hepatocellular carcinoma in Karachi. J Gastroenterol Hepatol 5: 1-6.

13. Liu Y \& Wu F (2010). Global burden of aflatoxin-induced hepatocellular carcinoma, a risk assessment. Environ Health Perspect 118: 818-24.

14. Bhurgri Y, Pervez S, Usman A, Khan JA, Bhurgri A \& Kasi Q (2002). Cancer patterns in Quetta (1998-1999). J Pak Med Assoc 52: 560-5.

15. Bhurgri Y, Bhurgri A, Hassan SH, Zaidi SH, Rahim A \& Sankaranarayanan R (2000). Cancer incidence in Karachi, Pakistan: first results from Karachi Cancer Registry. Int J Cancer 85: 3259.

16. Zaigham Abbas (2013). Hepatocellular Carcinoma in Pakistan. Journal of the College of Physicians and Surgeons Pakistan 23(11): 769-770.

17. Virginia Chih-Yi Sun, RN, MSN, ANP (2008). Symptom Management in Hepatocellular Carcinoma Clin $J$ Oncol Nurs 12(5): 759-766.

18. Jelic S \& sotiropoulos GC (2010). Hepatocellular carcinoma ESMO clinical practice Guidelines for diagnosis, treatment and follow -up annals of oncology 21 (s5): 59-64.

19. Li W, Min Y, Zhizhen Z, Yun Z \& Dengfu Y (2014). Circulating specific biomarkers in diagnosis of 
hepatocellular carcinoma and its metastasis monitoring. Tumor Biol 35: 9-20.

20. Chen DS, Sung JL \& Sheu JC (1984). "Serum $\alpha$-fetoprotein in the early stage of human hepatocellular carcinoma," Gastroenterology 86 (6): 1404-1409.

21. Poon Terence CW, Tai TY, Anthony TCC, Christine Y, Victor Y, Tony SKM, Conrad CY, Thomas WTL, Stephen KH \& Philip JJ (2003). Comprehensive Proteomic Profiling Identifies Serum Proteomic Signatures for Detection of Hepatocellular Carcinoma and Its Subtypes, Clinical Chemistry 49: (5) 752-760

22. Daia L, Pengfei R, Mei L, Haruhiko Ic, Eng MT \& Jian-Ying Z (2014). Using immunomic approach to enhance tumor-associated autoantibody detection in diagnosis of hepatocellular carcinoma Clin Immunol 152(0): 127139.

23. Feng R, Jianwen Y \& Chuang Z (2015). Calreticulin down-regulation inhibits the cell growth, invasion and cell cycle progression of human hepatocellular carcinoma cells. Diagnostic Pathology 10(149): 1-9.

24. He K, Xiaojie G, Yi L, Jingsong L, Ying $\mathrm{H}$, Dongmei $\mathrm{W} \&$ Jianguo $\mathrm{S}$ (2016). TUFM downregulation induces epithelial-mesenchymal transition and invasion in lung cancer cells via a mechanism involving AMPK-GSK3 $\beta$ signaling. Cellular and Molecular Life Science 73(10): 21052121. 